\title{
Nutritional aspects of metabolic bone disease in the newborn
}

\author{
Steven Ryan
}

Metabolic bone disease (MBD) in the newborn predominantly affects preterm neonates, although there are a few reports of babies with congenital rickets after maternal vitamin $\mathrm{D}$ deficiency. Features of MBD in preterm neonates include radiological abnormalities such as fractures, rickets, and osteoporosis; biochemical features such as raised blood alkaline phosphatase activity or hypophosphataemia; skeletal deformity such as rib cage softening and altered head shape; and diminished linear growth velocity.

MBD can arise from insufficient dietary minerals (calcium and or phosphorus), too little collagen, or abnormal collagen.

MBD mainly arises from dietary mineral deficiency in the newborn, although copper deficiency, as a result of abnormal collagen metabolism, has also been implicated. It is difficult to differentiate these two processes, because they often occur in the same patient.

The pathology of MBD in preterm neonates shows generalised skeletal mineralisation, a reduction in the amount of osseous tissue (osteoporosis), and a disordered metaphyseal cartilage plate similar to that seen in classic rickets. $^{1}$

\section{Nutritional aetiology of MBD in preterm neonates}

MINERAL DEFICIENCY

In 1980 Steichen, Gratton, and Tsang directly examined the effect of dietary mineral enhancement on bone mineralisation. ${ }^{2}$ Having contrasted the exponential requirement for calcium in utero (between 3.25 and 3.9 $\mathrm{mmmol} / \mathrm{kg} /$ day) with the usual estimated postnatal dietary calcium retentions (between 1.6 and $2.5 \mathrm{mmol} / \mathrm{kg} /$ day), they supplemented formula milk with calcium $(41.5 \mathrm{mmol} / \mathrm{l})$ and phosphorus $(20 \mathrm{mmol} / \mathrm{l})$ and were able to show, using photon absorptiometry, peripheral skeletal bone mineral accretion equivalent to that in utero. ${ }^{2}$ Without dietary mineral enhancement, bone mineral accretion is negligible. ${ }^{3}$ In effect Steichen et al were mimicking the increase in total body calcium content from $5 \mathrm{~g}$ at 26 weeks of gestation, to $30 \mathrm{~g}$ at full term. The results of this small study have not been replicated by others, possibly because the control group had a lower bone mineral content before supplementation was started.
Using formal balance studies, other groups showed rates of calcium and phosphorus retention equivalent to those seen in utero, with milk contents of calcium ( 31 to $37.5 \mathrm{mmol} / \mathrm{l}$ ) and phosphorus (21 to $27 \mathrm{mmol} / \mathrm{l}) .^{45}$ These studies were the basis for the concentrations of calcium and phosphorus found in current preterm cow's milk formulas used in the United States. Levels in European formulas tend to be somewhat lower.

The hypothesis that the dietary mineral deficit relative to the in utero experience is responsible for MBD and bone mineral deficiency is based on calcium requirements. Calcium deficiency is very rare and has been described only after the accidental omission of calcium from parenteral nutrition solutions. ${ }^{6}$ Phosphorus deficiency has a more direct association with overt MBD and this is felt to be because phosphorus and calcium are taken up differentially by the skeleton and other tissues. Ninety eight per cent of body calcium is located in bone mineral compared with $85 \%$ of phosphorus; the other $15 \%$ resides in other tissues. Consequently, at very low mineral intakes, phosphorus deficiency arises first, as the lean tissues take priority, leaving little for the skeleton.

Phosphorus deficiency is seen in preterm neonates who are fed unfortified human milk, ${ }^{7}$ and during parenteral nutrition, ${ }^{8}$ when phosphorus intake may be as low as 0.5 $\mathrm{mmol} / \mathrm{kg} / \mathrm{day}$, compared with the in utero requirement of 2.1 to $2.6 \mathrm{mmol} / \mathrm{kg} /$ day. Features of phosphorus deficiency are low blood phosphorus concentration $(<1 \cdot 2$ $\mathrm{mmol} / \mathrm{l}$ ), high tubular reabsorption of phosphorus $(>95 \%)$, and evidence of excess calcium in urine. ${ }^{7}$ Forty two per cent of human milk fed preterm neonates develop radiological evidence of rickets, ${ }^{9}$ associated with lower plasma phosphorus concentrations than seen in those without overt bone disease. Some degree of phosphorus deficiency seems to arise antenatally and is related to placental abnormality. ${ }^{9}$ This fits in with the association of a number of adverse antenatal factors with MBD of prematurity. ${ }^{10} \mathrm{MBD}$ defined by plasma alkaline phosphatase activity of $>1200$ IU/l occurs in $25 \%$ of neonates receiving unfortified pooled donor breast milk compared with $14 \%$ receiving a preterm formula. ${ }^{11}$ 
VITAMIN D DEFICIENCY

At one time vitamin $\mathrm{D}$ deficiency was felt to be the main cause of $\mathrm{MBD}$ in preterm neonates. ${ }^{12}$ This assumption had quite naturally arisen because of the similarity of rachitic changes in preterm neonates with those in older children with nutritional vitamin $D$ deficiency. In fact, preterm neonates have increased concentrations of 1,25 dihydroxyvitamin $\mathrm{D}$, the active hormone, which increase with age. ${ }^{13}$ In preterm infants with overt MBD, 1,25 dihydroxyvitamin $\mathrm{D}$ concentrations are even higher ${ }^{14}$ and fall with mineral supplementation. ${ }^{14}$ This suggests that the raised concentration of the hormone is a response to dietary mineral insufficiency.

A previous review ${ }^{15}$ suggested that a daily vitamin $D$ intake of 1000 IU is adequate, although daily doses as low as $400 \mathrm{IU}$ are probably adequate in otherwise healthy preterm neonates. End organ (gut) unresponsiveness to 1,25 dihydroxyvitamin $\mathrm{D}$ has been postulated in preterm neonates, ${ }^{16}$ and is supported by an apparent lack of any association between vitamin $\mathrm{D}$ intake and calcium absorption, ${ }^{17}$ but has not been confirmed.

\section{COPPER DEFICIENCY}

The bone abnormalities of copper deficiency are indistinguishable from those seen in MBD because of bone mineral deficiency in preterm neonates. Additional bone features of copper deficiency include subperiosteal new bone formation. Non-bone features include neutropenia, oedema, anaemia and late apnoea. All of these features can occur in preterm neonates for several different reasons, although neutropenia seems more specific for copper deficiency. ${ }^{18}$ It is difficult to be certain in the cases reported that improvement in rickets resulted from copper treatment, given the rapid healing which is known to occur in MBD of prematurity.

In a number of infants with bone disease ascribed to copper deficiency, blood copper concentrations lie within the $95 \%$ confidence interval for the population. ${ }^{19}$ In a group of 17 preterm neonates with fractures or rickets there was no reduction in blood copper concentration compared with those neonates without fractures. ${ }^{20}$ Additionally, serum copper estimation may not be the best way of assessing copper status, because reductions in red blood cell superoxide dismutase (a copper requiring enzyme) can occur in the presence of unchanged copper concentrations. ${ }^{21}$ The exact association between copper deficiency and MBD remains uncertain, although the presence of neutropenia may be a useful indicator.

\section{Prevention of MBD}

FORMULA FEEDING

If a preterm formula is tolerated overt MBD is unlikely. Preterm formulas in use in the United Kingdom contain between 17.5 and 27.5 $\mathrm{mmol} / 1$ of calcium and 13.2 and $20.3 \mathrm{mmol} / \mathrm{l}$ of phosphorus. Even at these concentrations in utero accretion may not be achieved, ${ }^{22}$ perhaps because of mineral precipitation in milk.
Despite the original report, ${ }^{2}$ it has not been convincingly shown that in utero rates of bone mineral accretion can be achieved with such formulas. Although theoretically sound, such an approach is probably unnecessary given the rapid catchup in bone mineralisation, fall in alkaline phosphatase activity, and improved phosphorus concentration which occur after 40 weeks of conception and through early infancy. ${ }^{23-26}$ The catchup in bone mineralisation has been expressed in terms of forearm bone mineral content (BMC $\mathrm{mg} / \mathrm{cm}$ ) and in terms of whole body BMC. ${ }^{27}$ Sparse data on lumbar spinal bone mineral density (BMD $\mathrm{mg} / \mathrm{cm}$ ) also suggest rapid catchup to values in infants born at full term. ${ }^{28}$ Whether full catchup in BMD occurs in most infants remains to be established.

Pohlandt $^{29}$ and Hillman et $a^{30}$ have suggested that in utero mineral accretion can only be achieved by using individually monitored supplementation with calcium and phosphorus, because of the natural interindividual variation in the processes of mineral absorption. Neonates who received doses adequate enough to permit simultaneous excretion of calcium $(>1.2 \mathrm{mmol} / \mathrm{l})$ and phosphorus $(>0.4 \mathrm{mmol} / \mathrm{l})$ in more than half of urine specimens, achieved such levels of mineral accretion. ${ }^{29}$ Given the complicated nature of this approach and without good evidence of long term benefits, it does not seem suited to routine clinical practice. Additionally, balance studies are only snapshots of net mineral absorption, with little information about day to day variability in mineral absorption in neonates.

In summary, modest mineral augmentation prevents overt MBD. Given the rapid catchup in bone mineralisation which occurs in the first year, and given that its effectiveness has not been conclusively shown, attempting to match in utero bone mineral accretion may not be necessary.

\section{HUMAN MILK}

In preterm neonates with nutritional hypophosphataemic rickets and fed with human milk, case reports show biochemical and radiological improvement in established MBD with phosphate supplementation at $0 \cdot 81$ $\mathrm{mmol} / \mathrm{kg} /$ day. Supplementation of human milk with $1.61 \mathrm{mmol} /$ day of phosphorus abolishes rickets, compared with an incidence of $42 \%$ in a control population. ${ }^{9}$

Fortification of human milk has been undertaken using a variety of proprietary and inhouse fortifiers, based on combinations of skimmed milk and calcium and phosphorus supplements. Fortification results in improved bone mineralisation, ${ }^{31} 32$ improved phosphate status, and reduced alkaline phosphatase activity. ${ }^{24} 33$ One study has suggested that powder fortification results in better bone mineralisation than that from liquid fortifier, perhaps related to the replacement of lactose with glucose polymer; lactose is felt to enhance dietary calcium absorption. ${ }^{31}$ Proprietary fortifiers in the United Kingdom are available as powders. 
PARENTERAL NUTRITION

Enhanced calcium and phosphorus content of parenteral nutrition solutions reduces the risk and severity of MBD. Standard solutions contain up to $1 \mathrm{mmol} / \mathrm{kg} /$ day of both calcium and phosphorus. Enhancement to $1.9 \mathrm{mmol} / \mathrm{kg} /$ day calcium and $2.4 \mathrm{mmol} / \mathrm{kg} /$ day of phosphorus is associated with a reduction in the incidence of hypophosphataemia, fewer $x$-ray abnormalities, and improved bone mineralisation..$^{34} 35$ It has been calculated that to match in utero retention, $3 \mathrm{mmol} / \mathrm{kg} /$ day of calcium and $2 \cdot 8$ $\mathrm{mmol} / \mathrm{kg} /$ day of phosphorus are required. ${ }^{36}$ This molar ratio, slightly in excess of 1 , is generally considered to allow the best retention of calcium and phosphorus. The aim of treatment should be to keep the blood phosphorus concentration above $1.2 \mathrm{mmol} / \mathrm{l}$.

To enhance parenteral nutrition solutions requires careful discussion with the pharmacy department as the solubility of calcium and phosphorus depends on other components within the solutions, the order in which they are combined, and the ambient temperature.

One way around this problem is to use organic phosphorus salts which do not precipitate with calcium, which are stable in solution $^{37}$ and achieve equivalent retentions to standard salts in similar doses. ${ }^{38}$ Results of studies are awaited and must include assessment of urinary calcium excretion and the incidence of nephrocalcinosis. Hypercalcuria and nephrocalcinosis are associated with the use of parenteral nutrition in ill preterm neonates, and increased parenteral administration of calcium and phosphorus may increase the risk of these problems.

Vitamin D intakes of $30 \mathrm{IU} / \mathrm{kg} /$ day maintain adequate vitamin $\mathrm{D}$ status in parenterally nourished babies, as the main action of vitamin $\mathrm{D}$ is on gut absorption of calcium. Excess vitamin $\mathrm{D}$ is theoretically harmful as, in the presence of a low calcium intake, it may cause negative calcium balance by increasing bone demineralisation. ${ }^{39}$

\section{After discharge}

HUMAN MILK FEEDS

Two studies have been conducted of breast feeding continued after discharge in preterm neonates, who had all been fed human milk with fortifier in the neonatal nursery. Both showed evidence of impaired mineralisation relative to formula fed infants. Blood phosphorus concentration was lower and serum alkaline phosphatase activity was higher throughout the first year of life. ${ }^{4041}$ This, despite the ameliorating effect of a more varied diet with weaning.

Forearm bone mineral content was also lower at 1 year of age in human milk fed than in formula fed infants. ${ }^{41}$ The deficit in bone mineral content is fully established by 25 weeks of age, after which it remains relatively unchanged. This suggests that a relatively brief period of dietary mineral supplementation after discharge will prevent it. Calcium and phosphorus supplementation for breast fed infants during this period reduced hypophosphataemia from about $50 \%$ to $10 \%$, and may be a useful strategy in enhancing bone mineral acquisition. ${ }^{42}$

\section{FORMULA FEEDING}

Nutrient enriched follow-on formulas have been developed for use in preterm neonates who have reached the upper weight limit for hospital preterm formulas. In addition to improved growth assessed by weight gain, the higher mineral content of the milk (17.5 $\mathrm{mmol} / \mathrm{l}$ calcium and $11.3 \mathrm{mmol} / \mathrm{l}$ phosphorus) resulted in improved peripheral skeletal bone mineral content three months after discharge, the same difference persisting nine months after discharge. ${ }^{43}$ This suggests, as above, ${ }^{41}$ that the most important period of skeletal mineralisation occurs immediately after hospital discharge, when the infant may be developing increased vitamin $\mathrm{D}$ sensitivity. A short period of dietary mineral enhancement, say three months of an enriched formula, may be adequate in maximising bone mineral acquisition. In this study the control formula had a phosphorus and calcium content towards the lower end of the range used for full term milks, and had another milk been used for the controls, the difference in BMC may have been less striking.

\section{Treatment of established MBD}

Treatment is undertaken on an empirical basis. A logical approach is to consider the individual nutrients discussed above. If a preterm formula, follow-on preterm formula, or fortified human milk are used, mineral insufficiency is unlikely. Phosphorus concentration should be checked and if hypophosphataemia (serum phosphorus concentration $<1 \cdot 2$ $\mathrm{mmol} / \mathrm{l})$ or a high $(>95 \%)$ tubular reabsorption of phosphorus are observed, phosphorus supplementation, starting at $1.8 \mathrm{mmol} /$ day should be started. ${ }^{9}$ If such a situation has resulted during parenteral nutrition, check that phosphorus intake has been maximised and if it has consider oral phosphate supplementation. There is no requirement to increase the total daily dose of vitamin $\mathrm{D}$ above 1000 IU/day, although in an infant with liver disease vitamin D status may need to be assessed.

The peak time for the appearance of rickets and fractures is around 36 to 40 weeks after conception. MBD at this stage reflects earlier nutritional compromise, as the preterm neonate is usually receiving adequate nutrition. In this situation further dietary changes may well be unnecessary.

Because the production of hydroxyapatite (bone mineral) produces metabolic acid and because preterm neonates are frequently acidotic, metabolic acidosis can be ameliorated by using phosphorus compounds which contain the smallest molar ratio of hydrogen ion.

\footnotetext{
1 Oppenheimer SJ, Snodgrass GJAI. Neonatal rickets Histopathology and quantative bone changes. Arch D Child 1980; 55: 945-9.

2 Steichen J, Gratton TL, Tsang RC. Osteopenia of prematurity: The cause and possible treatment. $\mathcal{f}$ Pediatr 1980
} 96: 528-34. 
3 Horsman A, Ryan SW, Congdon PJ, Truscott JG, James JR. Osteopenia in extremely low birthweight infants. Arch Dis Child 1989; 64: 485-8.

4 Rowe JC, Goetz CA, Carey DE, Horak E. Achievement of in utero retention of calcium and phosphorus accompanied by high calcium excretion in very low birth weight panied by high calcium excretion in very low birth weight

5 Giles MM, Fenton MH, Shaw B, et al. Sequential calcium and phosphorus balance studies in preterm infants. $\mathcal{f}$ Pediatr 1987; 110: 591-8.

6 Gutcher GR, Chesney RW. Iatrogenic rickets as a complication of a total parenteral nutrition program. Clin Pediatr 1978; 17: 817-9.

7 Rowe J, Rowe D, Horak E, et al. Hypophosphataemia and hypercalcuria in small premature infants fed human milk: 1984; 104: 112-7.

8 Koo WKK, Tsang RC, Succop P, Krug-Wispe SK, Babcock D, Oestreich AK. Minimal vitamin D and high calcium and phosphorus needs of preterm infants receiving parenteral nutrition. $\mathcal{F}$ Pediatr Gastroenterol Nutr 1989; ing parentera $225-33$.

9 Holland PC, Wilkinson AR, Diez J, Lindsell DRM. Prenatal deficiency and phosphate supplementation and rickets in very low birthweight infants. Lancet 1990; i: 697-701.

10 Griscom NT, Craig JN, Neuhauser EBD. Systemic bone disease developing in small premature infants. Pediatrics 1971; 48: 883-95.

11 Lucas A, Brooke OG, Baker BA, Bishop N, Morley R. High alkaline phosphatase and growth in preterm neonates. Arch Dis Child 1989; 64: 902-9.

12 Seino $Y$, Ishii $T$, Shimtsuji $T$, Ishida $M$, Yabuuchi $H$ Plasma active vitamin $\mathrm{D}$ concentrations in low birthweight infants with rickets and its response to vitamin D weight infants with rickets and its response

13 Markstead T, Asknes L, Finne PH, Aarskog D. Plasma concentrations of vitamin $\mathrm{D}$ metabolites in premature infants. Ped Res 1984; 18: 269-72.

14 Steichen J, Tsang RC, Greer FR, Ho M, Hug G. Elevated serum 1,25 dihydroxyvitamin $\mathrm{D}$ concentrations in rickets of very low-birth-weight infants. $\mathcal{f}$ Pediatr 1981; 99: 293-8.

15 Brooke OG, Lucas A. Metabolic bone disease in preterm infants. Arch Dis Child 1985; 60: 682-5.

16 Hillman LS, Salmons SJ. Evidence for a postconceptuallytimed development of classical vitamin $D$ responsiveness in human premature infants. Calcif Tiss Int 1983; 35: 695 .

17 Shaw JCL. Copper deficiency and non-accidental injury. Arch Dis Child 1988; 63: 448-55.

18 Bronner F, Salle BL, Putet G, Rigo J, Senterre J. Net calcium absorption in premature infants: results of 103 metabolic balance studies. Am $\mathcal{F}$ Clin Nutr 1992; 56: 1037-44.

19 Sutton AM, Harvie A, Cockburn F, Farquharson J, Logan RW. Copper deficiency in the preterm infant of very low birthweight: Four cases and a reference range for plasma copper. Arch Dis Child 1985; 60: 644-51.

20 Koo WW, Succop P, Hambridge KM. Sequential concentrations of copper and caeruloplasmin in serum from preterm infants with rickets and fractures. Clin Chem preterm infants

21 Barclay SM, Aggett PJ, Lloyd DJ, Duffy P. Reduced erythrocyte superoxide dismutase activity in low birth weigh
infants given iron supplements. Ped Res 1991; 29: 297-301

22 Schanler RJ, Abrams SA, Garza C. Bioavailability of calcium and phosphorus in human milk fortifiers and formula for very low birth weight infants. $\mathcal{F}$ Pediatr 1988 113: 95-100.

23 Congdon PJ, Horsman A, Ryan SW, Truscott JG, Durward $H$. Spontaneous resolution of bone mineral depletion in preterm infants. Arch Dis Child 1990; 65: 1038-42.

24 Gross SJ. Bone mineralisation in preterm infants fed human milk with and without mineral supplementation. $\mathcal{F}$ Pediatr 1987; 111: 450-8.
25 Schanler RJ, Burns PA, Abrams SA, Garza C. Bone mineralization outcomes in human milk-fed infants. Ped Res 1992; 31: 583-6.

26 Chan GM, Mileur LJ. Posthospitalisation growth and bone mineral status of normal preterm infants: Feeding with mother's milk or standard formula. Am $¥$ Dis Child 1985 139: 896-8.

27 Lapillonne AA, Glorieux FH, Salle BL, et al. Mineral balance and whole body bone mineral content in very lowbirth-weight infants. Acta Paediatr 1994; 405s: 117-22.

28 Tsukahara $H$, Sudo $M$, Umezaki $M$, et al. Measurement of lumbar spinal bone mineral density in preterm infants by dual-energy X-ray absorptiometry. Biol Neonate 1993; 64: 96-103.

29 Pohlandt F. Prevention of postnatal bone demineralization in very low-birth-weight infants by individually monitored supplementation with calcium and phosphorus. Ped Res 1994; 35: 125-9.

30 Hillman LS, Johnson LS, Lee DZ, Vieira NE, Yergey AL. Measurement of true absorption, endogenous fecal excretion, urinary excretion, and retention of calcium in term infants using a dual-tracer, stable isotope method. Pediatr 1993; 123: 444-56.

31 Moyer-Mileur L, Chan GC, Gill G. Evaluation of liquid or powdered fortification of human milk on growth and bone mineralisation status of preterm infants. $\mathcal{f}$ Pediat Gastroenterol Nutr 1992; 15: 370-4.

32 Greer FR, McCormick A. Improved bone mineralisation and growth in premature infants fed fortified own mother's milk. F Pediatr 1988; 112: 961-9.

33 Schanler RJ, Abrams SA, Garza C. Mineral balance studies in very low birth weight infants fed human milk. $\mathcal{F}$ Pediatr 1988; 113: 230-8.

34 Prestridge LI, Schanler RJ, Shulman RJ, Burns PA, Laine LL. Effect of parenteral calcium and phosphorus therapy on mineral retention and bone mineral content
birth weight infants. $₹$ Pediatr $1993 ; 122: 7618$.

35 MacMahon P, Blair ME, Treweeke P, Kovar IZ Association of mineral composition of neonatal intravenous feeding solutions and metabolic bone disease of prematurity. Arch Dis Child 1989; 64: 489-93.

36 Schanler RJ, Shulman RJ, Prestridge LL. Parenteral nutrient needs of very low birth weight infants. $\mathcal{F}$ Pediatr 1994 ; 125: 961-8.

37 Raupp P, Kries R van, Pfhal H-G, Manz F. Glycero- vs glucose phosphate in parenteral nutrition of premature glucose phosphate in parenteral nutrition of premature calcium/phosphorus compatibility. $¥$ Parent Enteral Nutr 1991; 15: 469-73.

38 Hanning RM, Atkinson SA, Whyte RK. Efficacy of calcium glycerophosphate vs conventional mineral salts for total parenteral nutrition in low-birth-weight infants: a randomised clinical trial. Am f Clin Nutr 1991; 54: 903-8.

39 Maierhofer WJ, Gray RW, Cheung HS, Lemann J. Bone resorption stimulated by elevated serum $1,25-(\mathrm{OH}) 2$-vitamin D concentrations in healthy men. Kidney Int 1983 24: 555-60.

40 Cooper PA, Rothberg AD, Pettifor JM. Early follow-up of very low birth weight infants after hospital discharge with respect to growth and mineral homeostasis. $f$ Pediatr Gastroenterol Nutr 1988; 7: 577-82

41 Abrams SA, Schanler RJ, Tsang RC, Garza C. Bone mineralisation in former very low birth weight infants fed either human milk or commercial formula: One-yea follow-up observation. $\mathcal{F}$ Pediatr 1989; 114: 1041-4

42 Hall RT, Wheeler RE, Rippetoe LE. Calcium and phosphorus supplementation after initial hospital discharge in breast-fed infants of less than 1800 grams birth weight. f Perinatol 1993; 13: 272-8.

43 Bishop NJ, King FJ, Lucas A. Increased bone mineral content of preterm infants with a nutrient enriched formula after discharge from hospital. Arch Dis Child 1993; 68: F573-8. 